\title{
The HemoCue ${ }^{\circledR}$, a point of care B-hemoglobin photometer, measures hemoglobin concentrations accurately when mixed in vitro with canine plasma and three hemoglobin-based oxygen carriers ( $\mathrm{HBOC})$
}

\author{
[Le photomètre de chevet HemoCue® fournit une mesure exacte de concentrations d'hémoglobine \\ combinées in vitro à du plasma canin et à trois transporteurs d'oxygène à base d'bémoglobine] \\ Jonathan S. Jahr MD, ${ }^{*}$ Fedor Lurie MD PhD, $\ddagger$ Bernd Driessen DVM PhD, $†$ Jessica A. Davis, $\ddagger$ \\ Robert Gosselin MT, $\ddagger$ Robert A. Gunther PhD $\ddagger$
}

Purpose: Accuracy of measurement of low hemoglobin concentrations using the HemoCue ${ }^{\circledR}$, a B-hemoglobin photometer (HemoCue AB, Angelholm, Sweden) may exhibit significant variability. Infusion of hemoglobin-based oxygen carriers (HBOC) results in low concentrations of plasma hemoglobin. Our study assessed B-hemoglobin photometer measurement accuracy of three HBOC: (hemoglobin glutamer-200 (bovine; Oxyglobin ${ }^{\circ}$, Biopure Corp., Cambridge, MA, USA); hemoglobin glutamer-250 (bovine; Hemopure ${ }^{\circledR}$, Biopure Corp, Cambridge, MA, USA), and hemoglobin-raffimer, (human; Hemolink ${ }^{T M}$, Hemosol, Inc., Toronto, Ontario, Canada).

Methods: In the laboratory, 45 split canine plasma samples were mixed with hemoglobin glutamer-200 $\left(8.13,16.25,32.5 \mathrm{~g} \cdot \mathrm{L}^{-1}\right.$ concentrations), 45 samples were mixed with hemoglobin glutamer-250 (8.13, 16.25, $32.5 \mathrm{~g} \cdot \mathrm{L}^{-1}$ concentrations), 45 with hemoglobin-raffimer $\left(12.5,25.0,50.0 \mathrm{~g} \cdot \mathrm{L}^{-1}\right.$ concentrations), and measured. Plasma samples without $\mathrm{HBOC}$ served as control. Hemoglobin concentration was determined by a laboratory analyzer (Coulter Corporation, Hiafeah, FL, USA) and B-hemoglobin photometer (HemoCue ${ }^{\circledR}$, Ångelholm, Sweden). Two independent technicians performed blinded sample measurements and randomly tested each sample five times. Results were analyzed according to Bland and Altman analysis.

Results: B-hemoglobin photometer demonstrated high repeatability for all three HBOCs. Repeatability coefficients were $0.37 \mathrm{~g} \cdot \mathrm{L}^{-1}$ and $0.48 \mathrm{~g} \cdot \mathrm{L}^{-1}$ for hemoglobin glutamer-200, $0.39 \mathrm{~g} \cdot \mathrm{L}^{-1}$ and 0.4 $\mathrm{g} \cdot \mathrm{L}^{-1}$ for hemoglobin glutamer-250 and $1.07 \mathrm{~g} \cdot \mathrm{L}^{-1}$ and $0.85 \mathrm{~g} \cdot \mathrm{L}^{-1}$ for hemoglobin-raffimer. An acceptable agreement was found between the B-hemoglobin photometer and the laboratory analyzer for all three HBOCs tested.

Conclusion: The B-hemoglobin photometer accurately determined the concentration of three $\mathrm{HBOC}$ solutions dissolved in canine plasma.

Objectif : La précision des mesures de faibles concentrations d'hémoglobine réalisées avec le HemoCue ${ }^{\circledR}$, photomètre pour B-hémoglobine (HemoCue AB, Angelholm, Suède), peut afficher une variabilité significative. Une perfusion de transporteurs d'oxygène à base d'hémoglobine (TOBH) entraîne de faibles concentrations d'hémoglobine plasmatique. Notre étude a évalué la précision du photomètre pour B-hémoglobine de trois TOBH : (l'hémoglobine glutamère-200 (bovine; Oxyglobin ${ }^{\circledR}$, Biopure Corp., Cambridge, MA, USA) ; l'hémoglobine glutamère-250 (bovine ; Hemopure ${ }^{\circledR}$, Biopure Corp, Cambridge, MA, USA) et l'hémoglobine-raffimère (humaine ; HemolinkTM, Hemosol, Inc., Toronto, Ontario, Canada).

Méthode : Au laboratoire, 45 échantillons divisés de plasma canin ont été combinés à de l'hémoglobine glutamère-200 (des concentrations de 8,13 - 16,25 - 32,5 $\left.\mathrm{g} \cdot \mathrm{L}^{-1}\right)$, 45 avec de l'hémoglobine glutamère$250\left(8,13-16,25-32,5 \mathrm{~g} \cdot \mathrm{L}^{-1}\right)$ et 45 avec de l'hémoglobine-raffimère $(12,5$ - 25,0 - 50,0 g.L-1), puis mesurés. Les échantillons

From the Departments of Anesthesiology, ${ }^{*}$ University of California Los Angeles, School of Medicine, and Charles R. Drew University of Medicine and Science, Martin Luther King Jr/Drew Medical Center, Los Angeles, California; the Department of Clinical Studies, $†$ New Bolton Center, University of Pennsylvania Kennett Square, Pennsylvania; and the Departments of Anesthesiology and Pain Medicine, Surgery, and Medical Pathology, University of California-Davis, School of Medicine, Sacramento, California, USA.

Address correspondence to: Dr. J.S. Jahr, Department of Anesthesiology, UC Los Angeles Center for the Health Sciences, Box 951778, Los Angeles, CA 90095, USA. Phone: 310-825-6761; Fax: 310-206-4626; E-mail: jsjahr@mednet.ucla.edu Accepted for publication September 26, 2001.

Revision accepted November 21, 2001. 
plasmatiques sans TOBH constituaient les témoins. La concentration d'hémoglobine a été déterminée à l'aide d'un analyseur de laboratoire (Coulter Corporation, Hiafeah, FL, USA) et du photomètre pour Bhémoglobine (HemoCue ${ }^{\circledR}$, Ångelholm, Sweden). Deux techniciens objectifs ont mesuré les échantillons sansen connaître la nature et ont testé chacun cinq fois de façon aléatoire. Les résultats ont été analysés à partir des méthodes de Bland et Altman.

Résultats : Le photomètre pour B-hémoglobine a démontré une grande fidélité pour les trois $\mathrm{TOBH}$. Les coefficients de répétabilité ont été de $0,37 \mathrm{~g} \cdot \mathrm{L}^{-1}$ et de $0,48 \mathrm{~g} \cdot \mathrm{L}^{-1}$ pour l'hémoglobine g/utamère-200; $0,39 \mathrm{~g} \cdot \mathrm{L}^{-1}$ et $0,4 \mathrm{~g} \cdot \mathrm{L}^{-1}$ pour l'hémoglobine glutamère-250 et 1,07 $\mathrm{g} \cdot \mathrm{L}^{-1}$ et $0,85 \mathrm{~g} \cdot \mathrm{L}^{-1}$ pour l'hémoglobine-raffimère. II y avait une concordance acceptable entre le photomètre pour B-hémoglobine et l'analyseur de laboratoire en regard des trois TOBH testés.

Conclusion : Le photomètre pour B-hémoglobine a permis de déterminer avec exactitude la concentration de trois solutions de TOBH dissoutes dans du plasma canin.

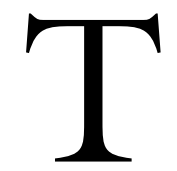

$\mathrm{H}$ Eblood hemoglobin $(\mathrm{Hb})$ concentration is an important variable directing transfusion therapy in patients suffering major blood loss. Hemoglobin concentration is measured routinely using automated counters, such as those produced by the Coulter Corporation. Although these counters are very accurate and reliable, transport of the samples to the laboratory delays the process and may delay treatment.

A point-of-care device for measuring blood $\mathrm{Hb}$, the B-hemoglobin photometer $(\mathrm{HemoCue} \AA$, Ångelholm, Sweden), provides rapid and convenient assessment of hemoglobin concentration. This device uses a chemically pretreated cuvette for the blood sample. The reagents deposited on the inner wall of the cuvette lyse the red cells and convert $\mathrm{Hb}$ into azide methemoglobin. The $\mathrm{Hb}$ concentration is calculated using spectrophotometric analysis with absorbence peaks at 565 and $880 \mathrm{~nm}$. The manufacturer claims the accuracy of the device to be within $\pm 3.0 \mathrm{~g} \cdot \mathrm{L}^{-1} \cdot 1$ A comparison between standard laboratory equipment and B-hemoglobin photometer showed a high correlation when using human blood. The HemoCue ${ }^{\circledR}$, however, has been shown to be more operator-dependent ${ }^{2}$ than other laboratory hemoglobin analyzers.

The use of hemoglobin-based oxygen carriers under development (HBOC) to diminish allogeneic blood transfusion therapy may require monitoring of the levels of plasma $\mathrm{Hb}$ during their administration. ${ }^{3}$ Therefore, the accuracy of the B-hemoglobin photometer with HBOCs should be validated. This study assessed the accuracy of photometer-based hemoglobin concentration determination using the $\mathrm{HemoCue}{ }^{\circledR}$ for three dif- ferent HBOCs: hemoglobin glutamer-200 (bovine; Oxyglobin ${ }^{\circledR}$, Biopure Corp, Cambridge, MA, USA), hemoglobin glutamer-250 (bovine; Hemopure ${ }^{\circledR}$, Biopure Corp, Cambridge, MA, USA), and hemoglobin-raffimer (human; Hemolink ${ }^{\mathrm{TM}}$, Hemosol, Inc., Toronto, Ontario, Canada) in varying concentrations mixed with canine plasma. One of these HBOCs (hemoglobin glutamer-200) is Food and Drug Administration (FDA) approved for veterinary use and indicated for canine anemia; hemoglobin glutamer-250 and hemoglobin-raffimer are currently undergoing or completing FDA phase III trials in the United States, and one, (hemoglobin glutamer-250) is approved for human use in South Africa. The published chemical and physical properties of the three HBOCs are shown in Table I.

\section{Methods}

The three HBOCs used in this study were obtained from different sources. The hemoglobin glutamer200 (Oxyglobin ${ }^{\circledR}$ ) was purchased through the veterinary pharmacy at University of California Davis School of Veterinary Medicine. The hemoglobin-raffimer $\left(\mathrm{Hemolink}^{\mathrm{TM}}\right)$ was donated by Hemosol, Inc., and the hemoglobin glutamer-250 (Hemopure ${ }^{\circledR}$ ) was donated to the team (JSJ and RG) in 1998 for study in coagulation laboratory equipment. ${ }^{4}$ The sample was preserved aseptically and anaerobically in a controlled temperature refrigerator. As this sample was not fresh, its colloid osmotic pressure (COP) was evaluated to determine if any protein denaturation had occurred, which would presumably increase the COP. The COP was measured at $25 \mathrm{mmHg}$, which follows the range in the literature of $17-25 \mathrm{mmHg}$ for this product. ${ }^{5,6}$ We therefore assumed that the product was intact and able to be evaluated in the present study.

In the laboratory, repeated measurements were conducted on samples of canine plasma obtained from one healthy animal mixed with HBOCs in different concentrations. For hemoglobin glutamer-200 and hemoglobin glutamer-250 the concentrations were 8.13, 16.25 and $32.5 \mathrm{~g} \cdot \mathrm{L}^{-1}$, for hemoglobin-raffimer they were 12.5, 25.0, and $50.0 \mathrm{~g} \cdot \mathrm{L}^{-1}$. Each dilution was divided into 15 samples (five for each of two technicians, and five for the laboratory analyzer). This resulted in a total of 135 samples, 45 samples for each of the two technicians, and 45 for the laboratory analyzer. Plasma samples containing no HBOC were used as controls. Hemoglobin concentration was determined using both an automated laboratory analyzer (Coulter STCS, Coulter Corporation, Hialeah, FL, USA.) and a bedside B-hemoglobin photometer (HemoCue $\left.{ }^{\circledR}\right)$. Two experienced, independent laboratory technicians (observer one and two) were blinded to sample number and per- 
TABLE I Physical and chemical properties of hemoglobin glutamer-200, hemoglobin glutamer-250, and hemoglobin-raffimer

\begin{tabular}{llll}
\hline & Hemoglobin glutamer-200 & Hemoglobin glutamer-250 & Hemoglobin-raffimer \\
\hline Hemoglobin concentration $\mathrm{g} \cdot \mathrm{dL}$ & 13 & 13 & 10 \\
p50 $(\mathrm{mmHg})$ & 34 & $36-38$ & 39 \\
pH & 7.8 & $7.6-7.9$ & 7.5 \\
Osmolality $\left(\mathrm{mOsm} \cdot \mathrm{kg}^{-1}\right)$ & 300 & $290-310$ & $64-500$ \\
Molecular weight $(\mathrm{kD})$ & average 200 & average 250 & $<10 \%$ \\
Unpolymerized hemoglobin & $<5 \%$ & $<5 \%$ & 26 \\
Methemoglobin & $<15 \%$ & $<10 \%$ & 25 \\
Colloid oncotic pressure $(\mathrm{mmHg})^{*}$ & 42 & 25 & \\
\hline
\end{tabular}

${ }^{*}$ Measured using Colloid Oncometer 4420 (Wescor, Logan, UT, USA).

TABLE II Plasma hemoglobin concentrations obtained by using Coulter analyzer (Coulter Corporation, Hialeah, FL, USA) and HemoCue ${ }^{\circledR}$ B-hemoglobin photometer (Aktiebolaget Leo Diagnostics, Helsigborg, Sweden)

\begin{tabular}{|c|c|c|c|c|c|c|c|c|c|}
\hline \multirow{3}{*}{$H B O C$} & \multicolumn{4}{|c|}{ Laboratory analyzer } & \multicolumn{4}{|c|}{ Bedside analyzer } & \multirow{3}{*}{$S D$} \\
\hline & $H b$ & Min & $\operatorname{Max}$ & $M$ & $S D$ & Min & $\operatorname{Max}$ & $M$ & \\
\hline & \multicolumn{8}{|c|}{ concentration $\left(g \cdot d L^{-1}\right)$} & \\
\hline \multirow[t]{3}{*}{$\mathrm{Hb}-200$} & 8.13 & 8.1 & 8.5 & 8.25 & 0.13 & 8 & 8.6 & 8.24 & 0.14 \\
\hline & 16.25 & 16.1 & 16.5 & 16.29 & 0.13 & 16.1 & 16.7 & 16.3 & 0.16 \\
\hline & 32.5 & 32.4 & 32.7 & 32.5 & 0.13 & 32.2 & 32.8 & 32.5 & 0.17 \\
\hline \multirow[t]{3}{*}{$H b-250$} & 8.13 & 8.1 & 8.4 & 8.19 & 0.11 & 8.1 & 8.3 & 8.2 & 0.067 \\
\hline & 16.25 & 16.1 & 16.4 & 16.26 & 0.107 & 16 & 16.5 & 16.25 & 0.143 \\
\hline & 32.5 & 32.2 & 32.6 & 32.43 & 0.142 & 32.1 & 32.7 & 32.46 & 0.19 \\
\hline \multirow[t]{3}{*}{ Hb-raffimer } & 12.5 & 12.2 & 12.6 & 12.41 & 0.137 & 12.2 & 12.6 & 12.4 & 0.133 \\
\hline & 25 & 24.8 & 25.7 & 25.26 & 0.288 & 24.3 & 26.1 & 25.23 & 0.333 \\
\hline & 50 & 49.7 & 51.1 & 50.14 & 0.42 & 49.7 & 51.1 & 50.2 & 0.397 \\
\hline
\end{tabular}

$\mathrm{Hb}$ level=blood hemoglobin (HBOC, hemoglobin-based oxygen carriers) plasma concentration in the tested samples; Min=minimal Hb concentration registered in the samples; Max=maximal $\mathrm{Hb}$ concentration registered in the samples; $\mathrm{M}=$ mean $\mathrm{Hb}$ concentration registered in the samples; $\mathrm{SD}=$ standard deviation.

formed the photometer measurements. Each operator randomly tested each of the 45 samples. The Bland and Altman analysis was used for repeatability estimation, and for measuring agreement between two methods using repeated measurements. ${ }^{7}$

Results

All control samples consistently demonstrated 0 concentration of hemoglobin when tested using both instruments.

\section{Hemoglobin glutamer-200}

The mean difference between two observers was $0.003 \pm 0.474 \mathrm{~g} \cdot \mathrm{L}^{-1}$ and did not depend on hemoglobin concentration (Figure 1). The mean difference in values between the laboratory analyzer and $\mathrm{B}$ hemoglobin photometer was $0.002 \pm 0.116 \mathrm{~g} \cdot \mathrm{L}^{-1}$. Repeatability coefficients were $0.37 \mathrm{~g} \cdot \mathrm{L}^{-1}$ for the first observer, $0.48 \mathrm{~g} \cdot \mathrm{L}^{-1}$ for the second observer, and 0.36 $\mathrm{g} \cdot \mathrm{L}^{-1}$ for the laboratory analyzer. When comparing values obtained from the laboratory analyzer with those obtained from B-hemoglobin photometer, the 95\% confidence interval for the lower limit of agree- ment was -0.515 to $-0.111 \mathrm{~g} \cdot \mathrm{L}^{-1}$, and for the upper limit of agreement was from 0 to $0.404 \mathrm{~g} \cdot \mathrm{L}^{-1}$.

\section{Hemoglobin glutamer-250 (bovine)}

The mean difference between two observers was $0.020 \pm 0.350 \mathrm{~g} \cdot \mathrm{L}^{-1}$ and did not depend on hemoglobin concentration (Figure 2). The mean difference in values between the laboratory analyzer and $\mathrm{B}$ hemoglobin photometer was $0.006 \pm 0.294 \mathrm{~g} \cdot \mathrm{L}^{-1}$. Repeatability coefficients were $0.39 \mathrm{~g} \cdot \mathrm{L}^{-1}$ for the first observer, $0.40 \mathrm{~g} \cdot \mathrm{L}^{-1}$ for the second observer, and 0.34 $\mathrm{g} \cdot \mathrm{L}^{-1}$ for the laboratory analyzer. When comparing values obtained from the laboratory analyzer with those obtained from B-hemoglobin photometer, the 95\% confidence interval for the lower limit of agreement was -0.725 to $-0.097 \mathrm{~g} \cdot \mathrm{L}^{-1}$, and for the upper limit of agreement was from 0 to $0.629 \mathrm{~g} \cdot \mathrm{L}^{-1}$.

\section{Hemoglobin-raffimer}

The mean difference between two observers was $0.007 \pm 0.620 \mathrm{~g} \cdot \mathrm{L}^{-1}$ and did not depend on hemoglobin concentration (Figure 3 ). The mean difference in values between the laboratory analyzer and B- 


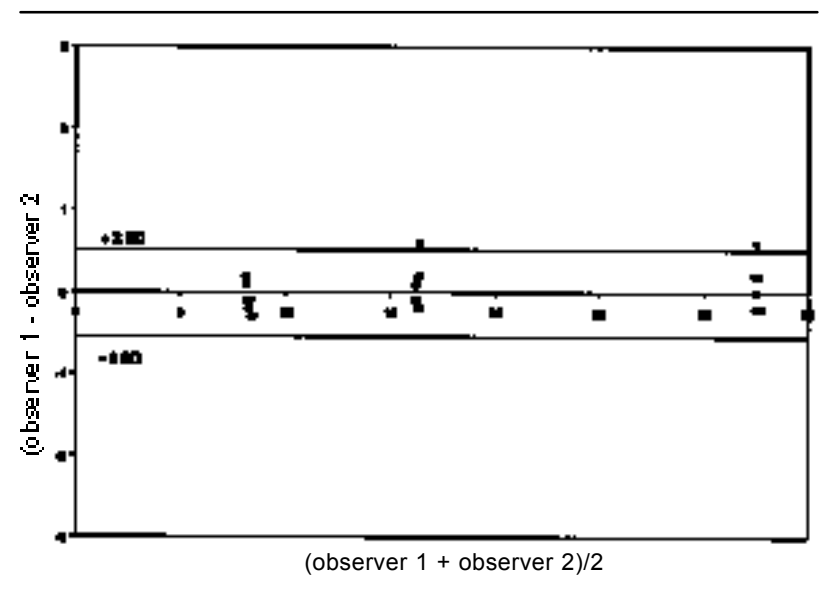

FIGURE I Variability plotted according to Bland and Altman. Ninety-five percent of agreement lines are drawn in plot. Differences between two measurements is denoted on vertical axis (observer 1 - observer two); the mean of two measurements is denoted on horizontal axis (observer $1+$ observer 2$) / 2$; g. $\mathrm{L}^{-1}$.

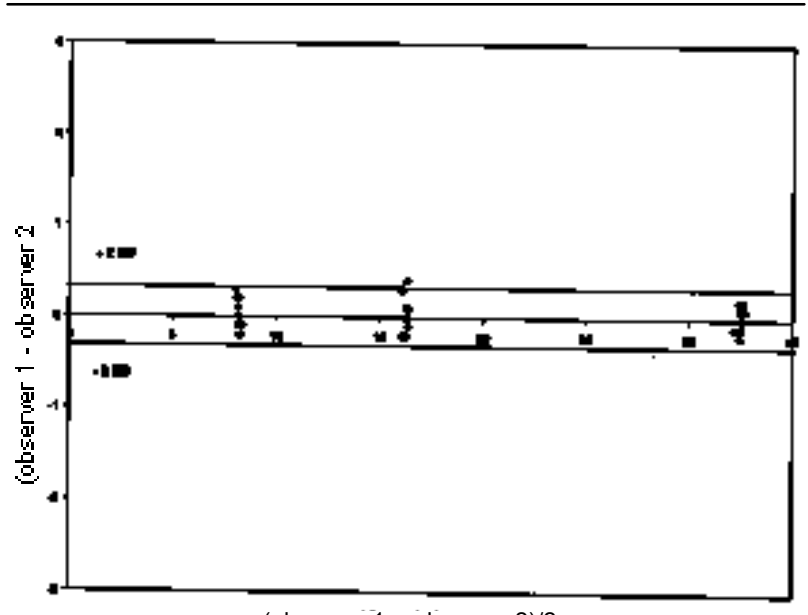

(observer $1+$ observer 2$) / 2$

FIGURE 2 Variability plotted according to Bland and Altman. Ninety-five percent of agreement lines are drawn in plot. Difference between two measurements is denoted on vertical axis (observer 1 - observer 2); the mean of two measurements is denoted on horizontal axis (observer $1+$ observer 2$) / 2 ; \mathrm{g} \cdot \mathrm{L}^{-1}$.

hemoglobin photometer was $0.013 \pm 0.764 \mathrm{~g} \cdot \mathrm{L}^{-1}$. Repeatability coefficients were $1.07 \mathrm{~g} \cdot \mathrm{L}^{-1}$ for the first observer, $0.85 \mathrm{~g} \cdot \mathrm{L}^{-1}$ for the second observer, and 0.84 $\mathrm{g} \cdot \mathrm{L}^{-1}$ for the laboratory analyzer. When comparing values obtained from the laboratory analyzer with those obtained from B-hemoglobin photometer, the 95\% confidence interval for the lower limit of agree-

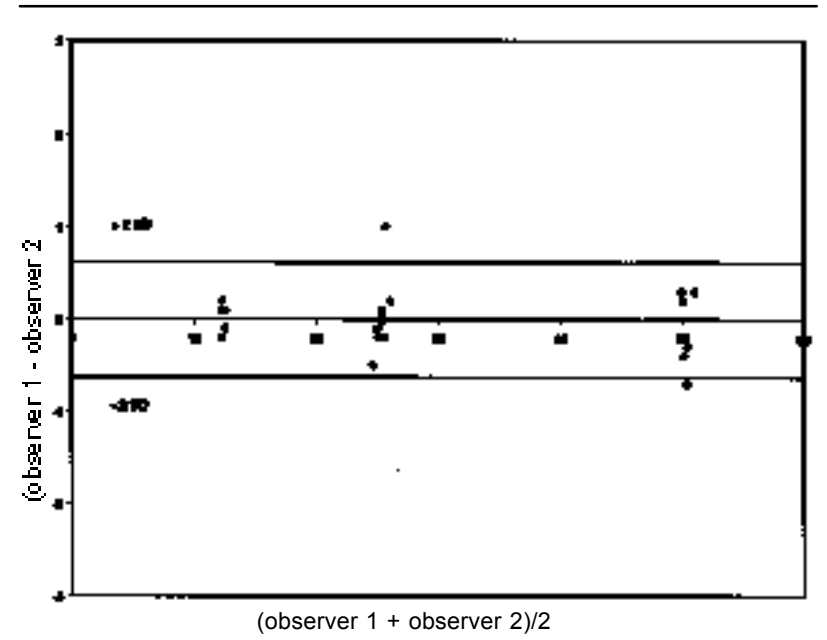

FIGURE 3 Variability plotted according to Bland and Altman. Ninety-five percent limits of agreement lines are drawn in plot. Difference between two measurements is denoted on vertical axis (observer 1 - observer 2); the mean of two measurement is denoted on horizontal axis (observer $1+$ observer 2$) / 2 ; g \cdot L^{-1}$.

ment was -1.871 to $-0.236 \mathrm{~g} \cdot \mathrm{L}^{-1}$, and for the upper limit of agreement was from 0 to $1.634 \mathrm{~g} \cdot \mathrm{L}^{-1}$.

Discussion

The hemoglobin concentration is a common element in making a decision whether transfusion is necessary or not. This decision should be made based on reliable and rapidly assessed laboratory tests. If a central laboratory is used for the purposes of transfusion monitoring, the time loss for blood sample transportation may create delays.

A point of care device, such as the B-hemoglobin photometer appears an appropriate solution for critical care settings and the operating room. Its clinical accuracy and reliability has been confirmed. ${ }^{8,9}$ Some technical aspects regarding the technology, however, have been emphasized in two reports. ${ }^{9,10}$ The dependence of the results upon the use of appropriate technique leads to some degree of intra-observer variability.$^{8-10}$

The results of hemoglobin concentration measurements with the B-hemoglobin photometer become particularly questionable when concentrations of hemoglobin in plasma are measured, especially as concentrations of the hemoglobin in the tested samples approach the limit of accuracy for the instrument. ${ }^{1}$ The use of HBOCs makes it clinically important to validate the B-hemoglobin photometer for measurement of plasma hemoglobin. Moreover, some of the HBOCs being under development are heterogeneous hemoglo- 
bins or chemically altered hemoglobins; therefore, they have optical properties different from normal human erythrocytic hemoglobin. These possibly can alter the accuracy of photometric measurements., ${ }^{4,11,12}$

Jaeger et al. compared the HemoCue to a standard hematology analyzer in the clinical setting and demonstrated "sufficient accuracy to support treatment decisions regarding blood transfusions". ${ }^{2}$ The article generated controversy regarding the use of Bland and Altman analysis, ${ }^{13}$ which we used to analyze our results. However, the two articles are not comparable, because we tested HBOC's in vitro, while Jaeger et al. tested patients' hemoglobins.

Lardi et al. ${ }^{8}$ evaluated the B-hemoglobin photometer in the clinical setting, similarly to Jaeger et al. Here again, the results are not comparable to ours, because no HBOC was tested. Rippmann et al. ${ }^{9}$ studied the Bhemoglobin photometer in vitro and in vivo, compared to a co-oximeter and reported a wider variability, but improved accuracy with multiple averaged evaluations. These results coincide with ours, except the variability appears wider than ours and may be due to the in vitro reconstitution of blood where red cells and fresh frozen plasma were mixed, possibly causing lysis of the red cells.

The study by McNulty et al. ${ }^{10}$ demonstrated a wide variability of bedside methods of hemoglobin assessment during hemodilution and after transfusion. However, photometry provided reasonably accurate results. This mirrors our own results. In addition we have shown that plasma hemoglobin determinations, in the absence of red blood cells, are accurate. It may be questioned whether our results can be extrapolated to the clinical scenario (dissolved HBOC in the absence of background hemoglobin, compared to the clinical situation of human plasma with red blood cells and HBOC). Obviously, extrapolation to the human clinical setting is impossible. However, veterinary use of HBOCs in canine models suggests this may be valid. ${ }^{11,12}$ This will require validation in human in vivo models.

In summary, our study shows that, in the clinically relevant range of plasma concentrations of three different HBOCs, the hemoglobin concentrations determined by use of B-hemoglobin Photometer are in agreement with values obtained by use of standard laboratory techniques. Both inter-observer and intraobserver repeatability were acceptable. Based on this in-pitro experiment, we conclude that the B-hemoglobin photometer is an appropriate device for rapid measurement of hemoglobin concentrations when HBOCs are added to plasma.
Acknowledgements

The authors acknowledge and thank Biopure Corp. for providing Hemopure ${ }^{\circledR}$, and Hemosol, Inc. for providing Hemolink ${ }^{\mathrm{TM}}$ for use in the study.

\section{References}

l HemoCue ${ }^{\circledR}$ (B-Hemoglobin Photometer). Operating Manual. Ångelholm, Sweden.

2 Jaeger M, Ashbury T, Adams M, Duncan P. Perioperative on-site haemoglobin determination: as accurate as laboratory values? Can J Anaesth 1996; 43 : 795-8.

$3 \mathrm{Jahr} J S$, Lurie F, Xi S, et al. A novel approach to measuring circulating blood volume: the use of a hemoglobin-based oxygen carrier in a rabbit model. Anesth Analg 2001; 92: 609-14.

4 Jahr JS, Lurie F, Gosselin R, Lin JS, Wong L, Larkin E. Effects of a hemoglobin-based oxygen carrier (HBOC201 ) on coagulation testing. Clin Lab Sci 2000; 13 : $210-4$.

5 Kasper SM, Walter M, Grune F, Bischoff A, Kasper SM, Erasmi H, Buzello $W$. Effects of a hemoglobin- based oxygen carrier (HBOC-201) on hemodynamics and oxygen transport in patients undergoing preoperative hemodilution for elective abdominal aortic surgery. Anesth Analg 1996; 83: 921-7.

6 Manning, JE, Katz LM, Brownstein MR, Pearce LB, Gawryl MS, Baker CC. Bovine hemoglobin-based oxygen carrier (HBOC-201) for resuscitation of uncontrolled, exsanguinating liver injury in swine. Shock 2000; 13: 152-9.

7 Bland JM, Altman DG. Measuring agreement in method comparison studies. Stat Methods Med Res 1999; 8: 135-60.

8 Lardi AM, Hirst C, Mortimer AJ, McCollum CN. Evaluation of the HemoCue for measuring intra- operative haemoglobin concentrations: a comparison with the Coulter Max-M. Anaesthesia 1998; 53: 349-52.

9 Rippmann CE, Nett PC, Popovic D, Seifert B, Pasch T, Spabn DR. Hemocue, an accurate bedside method of hemoglobin measurement? J Clin Monit 1997; 13: 373-7.

10 McNulty SE, Torjman M, Grodecki W, Marr A, Schieren $H$. A comparison of four bedside methods of hemoglobin assessment during cardiac surgery. Anesth Analg 1995; 81: 1197-202.

11 Jahr JS, Lurie F, Driessen B, et al. Validation of oxygen saturation measurements in a canine model of hemoglobin based oxygen carrier (HBOC) infusion. Clin Lab Sci 2000; 13: 173-9.

12 Jahr JS, Driessen B, Lurie F, Tang Z, Louie RF, Kost G Oxygen saturation measurements in canine blood containing hemoglobin glutamer-200 (bovine): in vitro 
validation of the Nova CO-oximeter. Vet Clin Path 2001; 30: 39-45.

13 Mantha S, Roizen MF, Fleisher LA, Thisted R, Foss J. Comparing methods of clinical measurement: reporting standards for Bland and Altman analysis. Anesth Analg 2000; 90: 593-602.

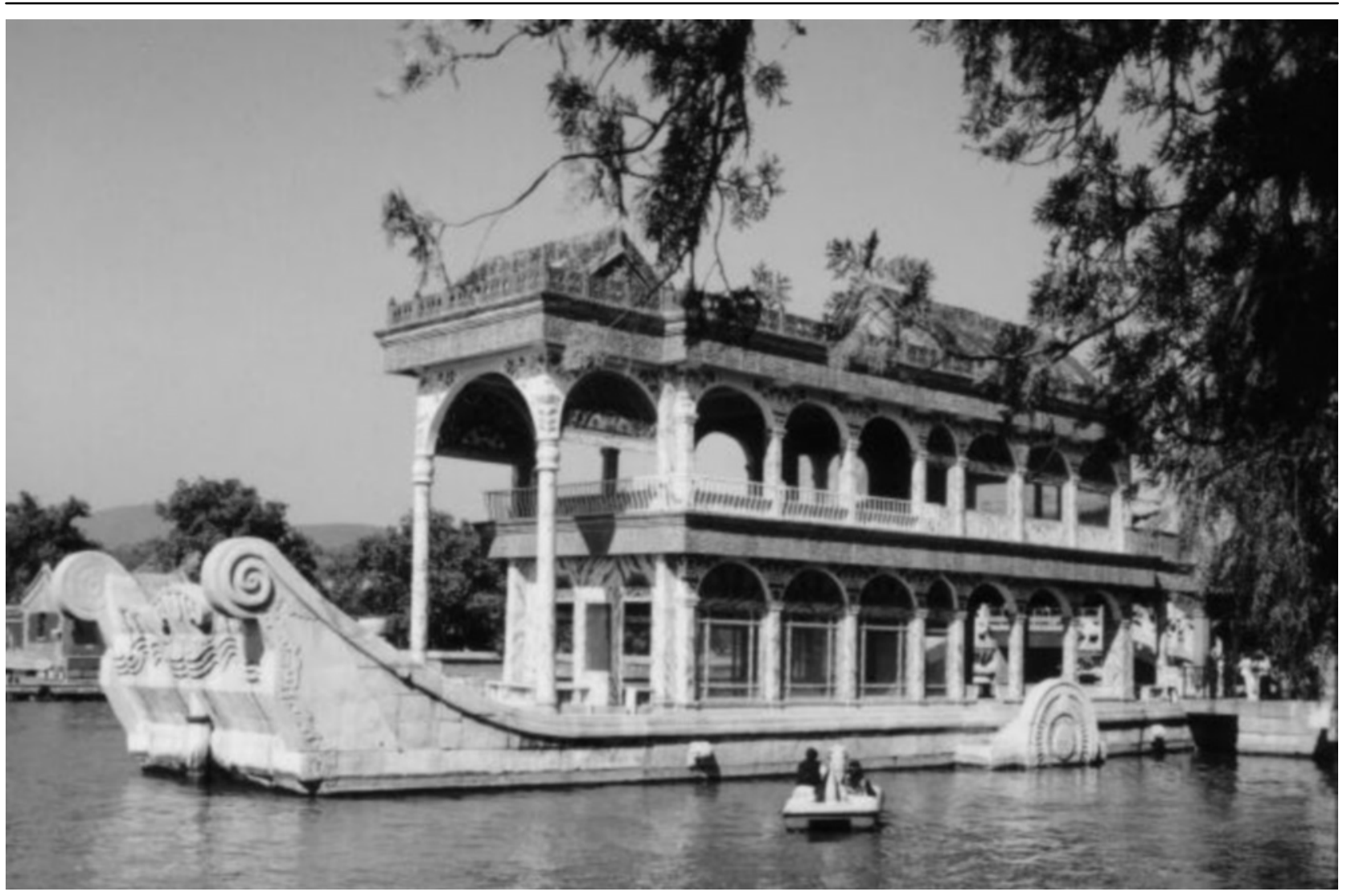

